\title{
Intervening Foreign Body
}

National Cancer Institute

\section{Source}

National Cancer Institute. Intervening Foreign Body. NCI Thesaurus. Code C87027.

An artifact resulting from the presence of a foreign body between the target and the receiver. 